\title{
Alcohol's Effects on Women's Risk Detection in a Date-Rape Vignette
}

\author{
Marci Loiselle, PhD; Wayne R. Fuqua, PhD
}

\begin{abstract}
Researchers have established that alcohol is a risk factor for date rape for both victims and perpetrators. Objective: The authors tried to experimentally address the link between alcohol consumption and women's risk detection abilities in a risky sexual vignette. Participants: The authors recruited 42 women from undergraduate classrooms at a large midwestern university and randomly assigned them to drink an alcoholic (.04 blood alcohol content) or a placebo beverage. Methods: Participants completed self-report inventories and listened to a date-rape audiotaped vignette, which began with consensual sexual behavior and culminated in date rape, and the authors asked them to determine if and when the man should refrain from making further sexual advances. Results: Student's $t$ tests and Pearson $r$ correlations showed that women who consumed alcohol and exhibited high levels of rape myth acceptance showed a significant decrease in risk recognition ( $p=.000$ and .001 , respectively). Conclusion: These findings highlight the significance of even small amounts of alcohol on behavior and cognition in women who are self-reported experienced drinkers.
\end{abstract}

Keywords: alcohol consumption, intoxication, rape, risk detection, sexual assault, women's perceptions

$\mathbf{R}$ ape is the sexual penetration of a person against his or her will by the use of force, by the threat of force, by verbal coercion, or by the inability to consent because of the impaired mental status or age of the victim. ${ }^{1}$ The lifetime prevalence of sexual assault for women in the general population is estimated to be between $13 \%$ and $25 \% .^{2}$ Benson et $\mathrm{al}^{3}$ estimated that 1 in 4 college-aged women has been the victim of a rape; $84 \%$ of victims knew their assailants, and $57 \%$ of these assaults occurred while on dates. The prevalence of date rape is also higher among college students than it is outside of college communities. Women aged 16 to

Dr. Loiselle is with the University of North Carolina-Chapel Hill, and Dr. Fuqua is with Western Michigan University's Department of Psychology.

Copyright () 2007 Heldref Publications
24 years are in the highest risk category for date rape-more than 4 times greater than any other group. ${ }^{4}$

Alcohol is frequently cited as a risk factor for date rape. Benson et $\mathrm{al}^{3}$ reported that in a general sample of victims and perpetrators of date rape, $73 \%$ of assailants and $55 \%$ of victims were under the influence of alcohol at the time of the attack. Heavy use of alcohol is strongly associated with an increased risk for date rape. ${ }^{5}$ In a survey of college students, Koss ${ }^{2}$ found that alcohol use was one of the 4 strongest predictors for date rape. The use of alcohol in date rape occurs twice as often as does the use of force. ${ }^{6}$

\section{Alcohol and Sexual Assault}

A number of researchers found an association between alcohol and sexual assault. ${ }^{4,7-12}$ The proportion of victims to perpetrators who consumed alcohol prior to a sexually aggressive incident range from $50 \%^{7,13}$ to as high as $80 \% .{ }^{6,14}$ In addition, a woman's level of alcohol consumption is more highly correlated with completed than with attempted rapes, ${ }^{15}$ as well as with an increased severity of sexual assault. ${ }^{16-17}$ However, Breitenbecher ${ }^{18}$ found that women are likely to underestimate the role of alcohol as a personal risk factor for sexual assault.

Alcohol may impair a woman's ability to resist unwanted sexual advances. Intoxicated women have reported participating in greater levels of consensual sexual activity with the perpetrator immediately prior to a sexual assault and offered less resistance than did nonintoxicated women during an assault. ${ }^{19}$ Alcohol may result in a slower reaction time and a less effective response to an attack. ${ }^{19}$ Nurius $^{14}$ found that alcohol decreases a woman's capacity to engage in defensive and effective physical resistance, particularly if she is caught off-guard by a perpetrator.

One of the mechanisms by which alcohol use may contribute to elevated risk of sexual assault is through the impairment of a woman's ability to detect risky sexual cues, one of the first steps in taking preventive and protective 
action. Early recognition that a social situation may become threatening can help prevent sexual aggression. ${ }^{20}$ Abbey $^{21}$ found that early and prompt verbal and physical resistance is of utmost importance in successfully escaping rape attempts.

Dating situations contain many ambiguous cues, some of which may be associated with positive and negative consequences (eg, sexual coercion and assault). ${ }^{20}$ Thus, early detection and correct interpretation of social cues is complicated, even without the influence of other factors, such as alcohol, social expectancy, and motivational variables. Further underscoring the importance of research on the influence of alcohol on sexual assault risk is evidence that alcohol may increase men's focus on feelings of sexual arousal and entitlement rather than on more distal cues, such as the woman's discomfort or the potential for later punishment. ${ }^{22}$

Few researchers have investigated the influence of alcohol consumption on a person's ability to detect signals associated with sexual assault. We asked participants to listen to an audiotape of a dating interaction between male and female actors that becomes gradually more coercive and eventually culminates in a rape. We instructed the participants to indicate the point in the tape where the male actor should refrain from making further sexual advances. Men who consumed alcohol allowed the tape to progress significantly longer (and to more coercive sexual demands) than did men who did not consume alcohol $(p<.001) .{ }^{23}$ In a follow-up study, the level of alcohol consumption was manipulated in aggressive and nonaggressive men. ${ }^{24}$ Aggressive and nonaggressive men who consumed alcohol took significantly longer to indicate the point in the audiotape analogue when the man should refrain from making further sexually aggressive advances than did men who did not consume alcohol. This suggests that nonaggressive males behave similarly to aggressive males when under the influence of alcohol. We suggest that future studies use this methodology to investigate how alcohol consumption interferes with a woman's risk detection ability.

\section{Overview of Study and Hypotheses}

The suggestion to study the influence of alcohol consumption on women is compatible with recent calls for research to identify causal variables in sexual assault and variables interfering with accurate risk detection. ${ }^{25}$ Experts have suggested that future research address the critical question of whether alcohol consumption itself decreases a woman's ability to detect risk of sexual assault. ${ }^{20,26} \mathrm{We}$ addressed this issue using a laboratory analogue for risk detection in naturalistic situations in which we assessed women's latency in detecting threatening stimuli using an audiotape vignette. Participants also completed self-report inventories to measure levels of rape myth acceptance, sexual communication and assertiveness, and history of sexual assault. We assigned women randomly to 1 of 2 conditions: Alcohol Group or Placebo Control Group. After consuming a beverage, participants listened to an audiotaped vignette and indicated when further sexual advances should cease. Our main hypothesis was that the consumption of alcohol would significantly increase the response latency to detect increasing levels of risk in a daterape vignette as compared with the Placebo Control Group. We also hypothesized that women with higher levels of rape myth acceptance and less effective sexual communication and sexual assertiveness skills would have significantly increased response latency scores.

\section{METHODS}

All research procedures were in accordance with the federal recommended requirements for alcohol administration studies by the National Institute on Alcohol Abuse and Alcoholism ${ }^{27}$ and the Human Subjects Institutional Review Board to increase subject protection and to conform to standard guidelines.

\section{Subjects}

We recruited 42 women aged 21-27 years $(M=21.9, S D$ $=1.38$ years) from undergraduate classrooms at Western Michigan University. White women constituted $85 \%$ of the sample, 3.4\% were Hispanic, 3.4\% were African American, $1.7 \%$ were Asian, and $1.7 \%$ were Native American. All participants were aged at least 21 years. On a screening survey, they reported an average of $5.85(S D=5.15)$ standard drinks per week and $3.17(S D=2.10)$ standard drinks per sitting.

\section{Procedure}

\section{Initial Screening}

We recruited subjects through classroom announcements and posted recruitment signs. Administrators gave subjects extra credit for their participation. We required volunteers to bring a designated driver to the session to facilitate a ride home. We screened all subjects for the following medical and psychological conditions that would preclude participation: (1) alcohol naivety; (2) pregnancy, as verified by an over-the-counter pregnancy test; (3) agreement to not drive or operate machinery for 12 hours after participation if they consumed alcohol; and (4) age older than 21 years. We scheduled all subjects for appointments during days 1-14 of their menses (the proliferative phase) to reduce the risk of false negative pregnancy test results.

\section{Laboratory Procedures}

We verified age (aged older than 21 years) via 2 forms of identification, 1 being a driver's license. We asked each subject to self-administer an over-the-counter pregnancy test; no positive results (eg, pregnancy) were achieved. We excluded only 1 subject because she could not urinate onto the pregnancy test strip. Each subject completed the Sexual Experiences Survey (SES), the Rape Myth Acceptance Scale (RMAS), Sexual Assertiveness Survey (SAS), and the Sexual Communication Survey (SCS).

A breathalyzer (the Intoxilyzer S-D2 Breathalyzer [CMI, Inc., Owensboro, KY]) confirmed that the subjects had not consumed alcohol prior to the session. We weighed each subject to determine the exact amount of alcohol or flattened tonic water to be administered. 
We gave the "Alcohol Group" $1.19 \mathrm{~g} / \mathrm{kg}$ of body weight of 80 proof Absolut vodka. We blended the vodka with tonic water in a 1:5 ratio mixture and included ice and lime juice; previous investigators indicated that when using this ratio, subjects could not detect the presence or absence of vodka at better than a chance rate. ${ }^{28-29}$ This amount of alcohol produced a peak blood alcohol content (BAC) of approximately $.04 \%$. We chose this BAC because previous researchers have reported that this level of intoxication was enough to affect perceptions and inhibitions. ${ }^{11,23}$ We gave subjects in the "Placebo Control Group" a 1:5 ratio of flattened tonic water to tonic water. To disguise drink content in the control group, we swabbed vodka around the rim of the glass and placed drops of lime juice and vodka in the tonic water. We asked subjects to not eat for 4 hours before attending the session to enhance absorption. We poured the contents of each mixture into 3 glasses of equal volume; subjects were given 15 minutes ( 5 minutes per drink) to consume all 3 drinks. Researchers ${ }^{11,23}$ used these standards in previous studies. No negative reactions to alcohol occurred. We asked the subject to sit and read neutral materials during absorption.

The Intoxilyzer S-D2 Breathalyzer measured BACs at 10, 17.5, 22.5, and 27.5 minutes after alcohol ingestion. All subjects in the Alcohol Group achieved peak BAC's within this time frame. We measured subjective intoxication levels (ILA) after a BAC of $.04 \% \pm .01 \%$ was achieved in the Alcohol Group or after 17.5 minutes in the Placebo Control Group. We asked each subject to listen to an audiotaped date-rape vignette and then obtained response latencies. No subjects became noticeably distressed by the content of the tape or requested that the tape should stop.

After completion, we gave all subjects a nonalcoholic beverage and a light snack. If alcohol was consumed during the course of the study, we retained subjects for 30 minutes after the last experimental task. For all subjects, we took a final breathalyzer reading, the researcher read a debriefing script and handed out a referral sheet, and the subject's designated driver then escorted her home.

\section{Stimulus Story}

The audiotaped vignette portrayed a man and a woman engaging in conversation and sexual activity at the man's apartment after a date. The vignette contained both inhibiting and disinhibiting cues for sexual contact. The coercive level of the man's requests for sexual activity and the intensity of the woman's refusals increased as the tape progressed. The vignette began with pleasant conversation regarding the date ( $0-13$ seconds) and progressed to kissing (13-68 seconds), fondling of the breasts (68-109 seconds), buttocks (109-190 seconds), and genitals (190-228 seconds), and culminated in nonconsensual sexual intercourse (228-292 seconds). The man used verbal persuasion, arguments, threats, and force to achieve sexual intercourse. The script, developed by Marx and Gross, ${ }^{30}$ has been used and validated in previous studies. ${ }^{23,30-32}$

\section{Measures}

\section{SES}

The SES is a self-report inventory that contains ten yesor-no questions regarding past sexual assault experiences. ${ }^{33}$ This measure has been extensively used in sexual assault research and was normed on 3,862 college students. ${ }^{34}$

\section{SAS}

The SAS consists of items assessing assertiveness regarding sexual initiation, sexual refusal, and prevention of pregnancy and sexually transmitted diseases. ${ }^{35}$ It is a general measure of one's level of sexual assertiveness.

\section{RMAS}

The RMAS is a 19-item self-report scale that assesses a subject's acceptance on a 7-point Likert scale $(1=$ strongly disagree; 7 = strongly agree) to prejudiced, stereotyped, or false beliefs about rape, rape victims, and rapists. ${ }^{36}$

\section{SCS}

The SCS is a 7-point Likert self-report scale $(1=$ never; $7=$ always) that assesses self-evaluation of one's ability to effectively state sexual needs and wants with one's partners. ${ }^{37}$

\section{Response Latency}

To simulate behavioral choices in a naturalistic setting, we used a response latency measure. We defined response latency as the length of time participants needed to determine when the man depicted in the vignette should refrain from making sexual advances toward the woman. ${ }^{30}$ We recorded response latencies in seconds with a stopwatch, with the timing commencing at the start of the vignette and ending when the subject pressed the "stop" button on the tape player. To minimize curiosity, we played the vignette until its completion after obtaining response latencies. We instructed the subject as follows:

Your task is to listen to the tape and immediately signal, by pressing this button, when the man should refrain from making further sexual advances. Even if you decide to press the button, you will be able to listen to the tape in its entirety from start to finish. If you become distressed or if I notice that you are becoming distressed, either you or I can stop the tape. Do you have any questions?

\section{ILA}

The first author developed the ILA to rate the level of perceived intoxication on a scale of 1-10 $(1=$ not intoxicated at all, $10=$ as intoxicated as I have ever been). We compared these scores with the assigned experimental condition to determine if subjective intoxication levels corresponded with actual levels of intoxication as measured by the breathalyzer. We also asked the subjects if their drinks contained alcohol and, if so, how many standard drinks they consumed. We administered this measure twice, once after peak BAC levels were achieved and once upon completion of the study. 


\section{RESULTS}

Groups did not differ significantly with regard to age, $t(.05,40)=.222 ; p=.826 ;$ relationship status, $t(.05,40)$ $=1.35 ; p=.184 ;$ race, $t(.05,40)=-.479 ; p=.635$; class standing, $t(.05,40)=.413 ; p=.682$; drinks per week, $t(.05,40)=-.805 ; p=.426$; and number of sexual partners, $t(.05,40)=.188 ; p=.852$.

\section{Sexual Victimization History}

\section{Preliminary Analyses}

We used the SES to screen sexual victimization history. If participants answered "yes" to any SES question, we asked follow-up questions about their age at the time of the incident, the perpetrator's relationship to them, frequency of incidents, whether alcohol or drugs were involved, whether physical force was involved, and whether the victim felt fearful of serious injury or death. Of the 42 participants, $31 \%$ reported being a victim of sexual assault. The mean number of assaults was $1.7(S D=1.46)$ at a mean age of 17.29 ( $S D=1.11)$. Twenty-eight percent of the endorsements involved a series of attacks. Of the reported assaults, $57 \%$ of subjects said their perpetrators were under the influence of alcohol (alone); $14.3 \%$ said the perpetrator was under the influence of both alcohol and drugs; and $28.6 \%$ said the perpetrator was not under the influence of any substance. In these cases, $57.1 \%$ of victims were under the influence of alcohol, $14.3 \%$ were under the influence of both alcohol and drugs, and $28.6 \%$ were under the influence of neither alcohol nor drugs. Fifty-seven percent of the assaults involved the perpetrator using physical force, and $14.3 \%$ of the sample said they were afraid of serious injury or death and felt that their lives were threatened.

\section{BAC}

Within 10 minutes of consumption of their final beverage, subjects in the Alcohol Group achieved a mean BAC of $.0395 \%$. Peak levels occurred for most subjects at $17.5 \mathrm{~min}$ utes, with a mean BAC of $.041 \%$. Only 2 subjects were unable to achieve the $.04 \% \mathrm{BAC} \pm .01 \%$ standard at 17.5 minutes; we gave them extra time to achieve the desired $\mathrm{BAC}$, and they were able to do so.

\section{ILA.}

On average, subjects in the Placebo Control Group reported a prescenario score of $1.38(S D=0.80)$ on the 10 point ILA scale $(1=$ least intoxicated to $10=$ most intoxicated), while indicating a perceived number of standard drinks of $1.50(S D=0.76)$. Subjects in the Alcohol Group scored an average of $3.70(S D=1.75)$, while indicating a perceived number of standard drinks of $2.69(S D=0.82)$. This difference is statistically significant $\left(F_{40}\right.$ values 11.788 and 12.361 , respectively; $p=.002$ ) for both the question of their perceived level of intoxication and the perceived number of standard drinks. We took ILA measures after completion of the scenarios, and they were also statistically significant $\left(F_{40}=4.831 ; p=.037\right)$, indicating that upon completion of the experimental tasks, the groups reported significantly different intoxication levels on a scale of 1-10 (experimental group: $M=3.70, S D=1.75$; control group: $M=1.38, S D=.060)$.

\section{Alcohol's Effect on Decision Latency}

Response latencies for the Placebo Control Group averaged 92.19 ( $S D=14.56)$ seconds indicating, on average, that the man should have ceased further sexual advances at the stage of the scenario where the woman said she was not comfortable with him touching her breasts and the man apologized. For the Alcohol Group, decision latency averaged $134.38(S D=39.05)$ seconds indicating, on average, that further sexual advances should have ceased shortly after the man touched the woman's breast once and buttocks twice without her permission, the woman became angry, and the man raised his voice and gave excuses to her rebuttals. Using an independent samples $t$ test to analyze average group differences, we analyzed decision latencies between groups to determine if any difference existed because of the alcohol manipulation. We found a significant difference between groups on the response latency variable, $t(.05,40)$ $=-4.639 ; p=.000$. As predicted, the response latency for the Alcohol Group was significantly longer than that of the Placebo Control Group.

\section{Correlations Between Decision Latency and Self-Report Variables}

To determine if data from the self-report variables correlated with decision latency, we conducted Pearson ProductMoment Correlations. We applied a Bonferroni correction to the number of comparisons, with a resulting $\mathrm{p}$ critical value of .005. Of the RMAS, SCS, SAS, and SES, only 1 correlated significantly with decision latency. The total RMAS and decision latency $r$ was $.510(p=.001)$. This indicated that one's total self-reported level of rape-myth acceptance as measured by the RMAS positively correlated with higher decision latency scores. We did not find any significant correlations with regard to female victims of sexual assault with decision latency. Although the correlation between decision latency and SAS approached significance $(p=.008)$, we did not find any other significant correlations (see Table I).

\section{COMMENT}

We were the first to experimentally demonstrate the impact of alcohol consumption on a woman's detection of sexual assault risk as measured by response latencies on a date-rape vignette. We found it interesting that the mean response latencies for the Alcohol Group were sufficiently long to allow the scenario to progress to the point where the man had engaged in behavior that would meet the criteria for criminal sexual conduct in most states. Furthermore, there was a significant positive correlation between total RMAS scores and decision latency.

Consistent with the main hypothesis, there were significant differences between the groups on decision latency scores on 
TABLE 1. Values Among the Rape Myth Acceptance Scale (RMAS), Sexual Experience Survey (SES), Sexual Assertiveness Scale (SAS), Sexual Communication Survey (SCS), and Decision Latency.

\begin{tabular}{lrrrrr}
\hline \hline & 1 & 2 & 3 & 4 & \multicolumn{1}{c}{5} \\
\hline 1. RMAS & 1.000 & .006 & .017 & .176 & $.001^{*}$ \\
2. SCS & .006 & 1.000 & $.003^{*}$ & .043 & .062 \\
3. SAS & .017 & $.003^{*}$ & 1.000 & .538 & .008 \\
4. SES & .176 & .043 & .538 & 1.000 & .244 \\
5. Decision Latency & $.001^{*}$ & .062 & .008 & .244 & 1.000 \\
& & & & & \\
${ }^{*} p<.005$ (two-tailed; after a Bonferroni correction). & \\
\end{tabular}

the date-rape vignette. This result is consistent with prior research results documenting an increase in decision latency scores as a result of an alcohol manipulation in men. ${ }^{23-24}$ Because researchers discovered significant results with men when investigating aggressive versus nonaggressive men on decision latency scores with an alcohol manipulation, ${ }^{24}$ it would be interesting for future investigators to determine if any differences exist between assertive versus passive women.

The positive RMAS and decision latency correlation was consistent with researchers who have shown that those with higher RMAS scores are more accepting of sexual violence. ${ }^{36}$ It may be that acceptance of traditional rape myths alters the manner in which women classify stimulus events, so that those events that function as serious risk stimuli for some women are treated as more innocuous stimuli by women with belief systems that incorporate rape myths. However, we found it surprising that in the present study there were no significant correlations between a woman's sexual abuse or assault history and risk detection latency. On the one hand, it would appear that women who have been the victim of sexual abuse or assault would be more cognizant of stimuli predictive of sexual assault than would others who have not been victimized. On the other hand, it may also be that they lack the requisite skills to identify danger.

The absence of a statistically significant correlation between the scores on the SCS and SAS and risk detection latencies are somewhat surprising. It is likely that the small sample size diminished the power of the SAS/decision latency correlation. However, the SCS and SAS are both measures of response skill or probability (ie, measures of assertiveness and communication), and the response latency measure was a signal-detection measure. It may well be that women who score high on the SCS and the SAS are more likely or more skilled to respond effectively in sexual situations but that the ability to detect signals of sexual assault risk measures a different skill dimension. Thus, it may be instructive to consider at least 2 different repertoires: the ability to detect risky situations and the ability to effectively respond to risky situations. Both skill sets would appear to be important for clinical efforts to train women to reduce their risk of sexual victimization.
These findings should be interpreted cautiously because of the large number of additional factors that could influence decision latency and risk detection. For example, a limitation of this study involved the laboratory nature of this experiment. Although laboratory experiments have high internal validity, there are obvious concerns about generalizability. Because of ethical constraints, researchers must rely upon indirect approaches to studying sexually abusive behavior. Real-life situations are likely to involve many variables that operate simultaneously. Researchers in laboratory experiments, such as this study, investigate variables in a simplified environment that are relatively insulated from outside contingencies. In addition, in natural settings, people often reach much higher levels of intoxication than the level used in this study. Alcohol is not a dichotomous variable; many different gradients of consumption can influence behavior. ${ }^{38}$ Subject expectations as well as the sample bias of volunteers may have also influenced these results, as we informed subjects of the nature of the study (eg, a study investigating sexual behavior and alcohol consumption).

Only those participants in the Alcohol Group ingested alcohol. However, a majority of participants in the Placebo Control Group reported that they too received alcohol, although in reality they ingested miniscule amounts of alcohol that was swabbed on the glass of an otherwise nonalcoholic beverage. Subjects in both groups reported being unable to distinguish whether their drinks contained alcohol. On average, subjects from the Placebo Control Group reported receiving 1.5 standard drinks, whereas subjects from the Alcohol Group endorsed receiving 2.69 standard drinks. Researchers in further studies should determine what, if any, placebo effect was present and should control for this by using an alcohol/no-alcohol $\times$ expect alcohol/expect no-alcohol design, similar to the design used by Abbey et al. ${ }^{11}$

We demonstrated that women who have consumed a moderate amount of alcohol are more impaired in their decisionmaking ability. Future studies should use this methodology to vary the amount of alcohol ingested, manipulate expectation, and determine differences in subjects' levels of assertiveness versus passivity and victimization history with an alcohol manipulation on a decision latency task. Preven- 
tion research should focus on sensitizing men and women to the effects of alcohol on risk detection to reduce one's optimization bias and the prevalence of rape.

\section{NOTE}

For comments and further information, address correspondence to Marci Loiselle, University of North Carolina at Chapel Hill, Comprehensive Transplant, CB 7600 Chapel Hill, NC 27514 (e-mail: marci_loiselle@med.unc.edu).

\section{REFERENCES}

1. Bohmer C. Acquaintance rape and the law. In: Parrot A, Bechhofer L, eds. Acquaintance Rape: The Hidden Crime. New York, NY: John Wiley \& Sons, Inc.;1991:317-333.

2. Koss M. Hidden rape: incidence, prevalence, and descriptive characteristics of sexual aggression and victimization in a national sample of college students. Aggressive Behav. 1988;14:136-146.

3. Benson D, Charlton C, Goodhart F. Acquaintance rape on campus: a literature review. J Am Coll Health. 1992;40:157-165.

4. Fritner M, Rubinson L. Acquaintance rape: the influence of alcohol, fraternity membership, and sports team membership. $J$ Sex Educ Ther. 1994;19:22-284.

5. Abbey A, McAuslan P, Zawacki T, Clinton AM, Buck PO. Attitudinal, experiential, and situational predictors of sexual assault perpetration. J Interpers Violence. 2001;16:784-807.

6 . Finley C, Corty E. Rape on campus: the prevalence of sexual assault while enrolled in college. J Coll Student Devel. 1993;43:113-117.

7. Seto M, Barbaree H. The role of alcohol in sexual aggression. Clin Psychol Rev. 1995; 15:545-566.

8. Abbey A, Zawacki T, Buck P, Clinton A, McAuslan P. Alcohol and sexual assault. Alcohol Health Res World. 2001;25: 43-51.

9. Abbey A, Harnish R. Perception of sexual intent: the role of gender, alcohol consumption, and rape supportive attitudes. Sex Roles. 1995;32:297-313.

10. Richardson D, Campbell J. Alcohol and rape: the effect of alcohol on attributions of blame for rape. Pers Soc Psychol Bull. 1982;8:468-476.

11. Abbey A, Zawacki T, McAuslan P. Alcohol's effects on sexual perception. J Stud Alcohol. 2002;61:688-697.

12. Bernat J, Calhoun K, Adams H. Sexually aggressive and nonaggressive men: sexual arousal and judgments in response to acquaintance rape and consensual analogues. J Abnorm Psychol. 1999;108:662-673.

13. Abbey A. Alcohol-related sexual assault: a common problem among college students. J Stud Alcohol. 2002;Suppl 14:118-128

14. Nurius P. Risk perception for acquaintance sexual aggression: a social-cognitive perspective. Aggression Violent Behav. 2000;5:63-78.

15. Chermack ST, Giancola PR. The relation between alcohol and aggression: an integrated biopsychosocial conceptualization. Clin Psychol Rev. 1997;17:621-649.

16. George WH, Stoner SA. Understanding acute alcohol effects on sexual behavior. Annual Rev Sex Res. 2000;11:92-124.

17. Testa M, Livingston J. Qualitative analysis of women's experiences of sexual aggression: focus on the role of alcohol. Psych Women Q. 1999;23:573-589.

18. Breitenbecher K. The association between the perception of threat in a dating situation and sexual victimization. Violence Vict. 1999;2:135-146.
19. Testa M, Livingston J, Collins R. The role of women's alcohol consumption in evaluation of vulnerability to sexual aggression. Exp Clin Psychopharmacol. 2000;8:185-191.

20. Norris J, Nurius P, Graham T. When a date changes from fun to dangerous: factors affecting a women's ability to distinguish. Violence Against Women. 1999;5:230-250.

21. Abbey A. Misperception as an antecedent of acquaintance rape: a consequence of ambiguity in communication between men and women. In: Parrot A, Bechhofer L, eds. Acquaintance Rape: The Hidden Crime. New York, NY: John Wiley \& Sons, Inc.; 1991:96-111.

22. Abbey A, McAuslan P, Zawacki T, Buck P. Alcohol-involved rapes: are they more violent? Psychol Women Q. 2002;26:99-109.

23. Marx B, Gross A, Juergens J. The effects of alcohol consumption and expectancies in an experimental date rape analogue. J Psychopathol Behav Assess. 1997;19:281-302.

24. Marx B, Gross A, Adams H. The effect of alcohol on the responses of sexually coercive men to an experimental rape analogue. Sex Abuse. 1999;11:131-145.

25. Yeater E, O'Donohue W. Sexual assault prevention programs: current issues, future directions, and the potential efficacy of interventions with women. Clin Psychol Rev. 1999;19:739-771.

26. Corbin W, Bernat J, Calhoun K, McNair L, Sears K. The role of alcohol expectancies and alcohol consumption on sexually victimized and nonvictimized college women. J Interpers Violence. 2001;16:297-311.

27. National Institute on Alcohol Abuse and Alcoholism. Recommended Council Guidelines on Ethyl Alcohol Administration in Human Experimentation. Rockville, MD: Dept of Health and Human Services, 1989.

28. Marlatt A, Demming B, Reid J. Loss of control drinking in alcoholics: an experimental analogue. J Abnorm Psychol. 1973;81:233-241.

29. Marlatt A, Rohsenow D. Cognitive processes in alcohol use: expectancy and the balanced placebo design. Adv Alc Subst Abuse. 1980;1:159-199.

30. Marx B, Gross A. Date-rape risk factors: an analysis of two contextual variables. Behav Modif. 1995;19:451-463.

31. Bernat J, Wilson A, Calhoun K. Sexual coercion history, calloused sexual beliefs and judgments of sexual coercion in a daterape analogue. Violence Vict. 1999;14:147-160.

32. Bernat J, Stolp S, Calhoun K. Construct validity and testretest reliability of a date rape decision latency measure. J Psychopathol Behav Assess. 1997;19:315-330.

33. Koss M, Oros C. Sexual Experiences Survey: a research instrument investigating sexual aggression and victimization. J Consult Clin Psychol. 1992;55:455-457.

34. Koss M, Gidycz C. Sexual Experiences Survey: reliability and validity. J Consult Clin Psychol. 1985;53:422-423.

35. Morokoff P, Quina K, Harlow L, et al. Sexual Assertiveness Scale (SAS) for women: development and validation. J Pers Soc Psychol. 1997;73:790-804.

36. Burt M. Cultural myths and supports for rape. J Pers Soc Psychol. 1980;38:217-230.

37. Naugle A. Identifying behavioral risk factors for repeated victimization using videotaped stimulus materials. Dissertation Abstracts International: B: The Sciences \& Engineering. 2000;61:1091.

38. Abbey A, Zawacki T, Buck P, et al. How does alcohol contribute to sexual assault? Explanations from laboratory and survey data. Alcohol Clin Exp Res. 2002;26:575-581. 
Copyright of Journal of American College Health is the property of Heldref Publications and its content may not be copied or emailed to multiple sites or posted to a listserv without the copyright holder's express written permission. However, users may print, download, or email articles for individual use. 